\title{
HISTÓRIA DA BOTÂNICA EM SANTA MARIA
}

\section{JOSÉ NEWTON CARDOSO MARCHIORI ${ }^{1}$ THAIS SCOTTI DO CANTO-DOROW²}

\section{RESUMO}

A história da Botânica em Santa Maria é investigada desde o tempo das famosas expedições dos viajantesnaturalistas do século XIX e, mais detidamente, a partir da criação da Faculdade de Farmácia, precursora da Universidade Federal de Santa Maria.

Palavras-chave: Botânica, História Regional, Santa Maria, Rio Grande do Sul.

\section{SUMMARY}

[The history of Botany in Santa Maria, Rio Grande do Sul state - Brazil].

The history of Botany in Santa Maria (Rio Grande do Sul state, Brazil) is investigated since the the time of the famous naturalist expeditions of nineteen century and, with more details, after the foundation of a Pharmacy Faculty in the city, the pioneer in the Federal University of Santa Maria.

Key words: Botany, Regional History, Santa Maria county, Rio Grande do Sul state (Brazil).

\section{INTRODUÇÃO}

Em carta $^{3}$ de 1963, enviada a Romeu Beltrão, o Dr. Friedrich von Huene ${ }^{4}$ manifestou surpresa ao saber que em Santa Maria já havia uma Universidade, pois em 1928, quando andou pela região em busca dos fósseis que lhe deram fama universal, ela pareceu-lhe uma "pequena cidade provinciana, bastante afastada da alta cultura"5. O eminente paleontólogo lembrou, mes-

1 Engenheiro Florestal, Dr. Professor Titular do Departamento de Ciências Florestais, UFSM. Bolsista de Produtividade em Pesquisa ( $\mathrm{CNPq}$ - Brasil). marchiori@pq.cnpq.br

2 Bióloga, Dra. Professora Associada do Departamento de Biologia, UFSM. thaisdorow@gmail.com

3 A carta, enviada por Romeu Beltrão em 9-5-1963, foi respondida por Friedrich von Huene em 22 de junho do mesmo ano. $\mathrm{O}$ texto manuscrito do cientista alemão foi publicado em 1965, no segundo número do Boletim do Instituto de Ciências Naturais da Universidade Federal de Santa Maria, à página 34.

${ }^{4}$ Nascido em Würtemberg, Alemanha (22-3-1875), o Dr. Friedrich von Huene foi Professor Extraordinário de Geologia e Paleontologia na Universidade de Tübingen. O material por ele recolhido no sítio da Alemoa (Santa Maria) e em Xiniquá (São Pedro do Sul), em 1928, permitiu-lhe descrever 10 gêneros e 15 espécies de sáurios fósseis, tema central de uma obra clássica da Paleontologia: Die Fossilen Reptilien des Südamerikanischen Gondwanalandes. mo assim, que "naquela época o Dr. Rau era médico em Santa Maria", muito provavelmente por ser uma das poucas pessoas na cidade com sólida formação e genuíno interesse pelas Ciências Naturais. A notícia não causaria espanto a um brasileiro, posto que o cultivo da ciência geralmente decorre de iniciativa oficial em nosso meio, não raro em locais distantes dos grandes centros e sem o respaldo da tradição, fatos, todavia, merecedores de estranheza ao olhar europeu, acostumado ao ambiente de multicentenárias instituições.

A vocação de Santa Maria como centro científico e cultural no interior do Rio Grande do Sul não resulta, entretanto, de um ato voluntarioso ou decisão meramente política, posto que resulta de um encadeamento de eventos acontecidos ao longo de sua história e que envolvem uma peculiaridade geográfica digna de nota: a cidade situa-se, precisamente, no centro do Rio Grande do Sul, a meio caminho entre o litoral e a fronteira oeste. Foi este posicionamento que colocou Santa Maria na rota dos grandes botânicos que percorreram o interior do Rio Grande do Sul no século XIX e, mais tarde, determinaram a sua vocação como nó ferroviário, entroncamento de estradas de rodagem, além de im- 
portante centro militar, comercial, educacional e de prestação de serviços. No campo educacional, por exemplo, Santa Maria já atraía estudantes de todo o interior do Estado no início do século XX, por suas escolas públicas e particulares $^{6}$, estando madura, portanto, para ambicionar vôo mais alto.

A história da Botânica em Santa Maria apresenta dois períodos distintos, separados entre si por um evento marcante para o futuro da ciência e cultura na cidade: a criação, em $1^{\circ}$ de outubro de 1931, da Faculdade de Farmácia ${ }^{7}$, precursora da Universidade Federal de Santa Maria. Até então, o cultivo da Scientia Amabilis era apenas objeto de diletantes e de eventuais naturalistas que andaram pela região, alguns deles, aliás, considerados entre os mais importantes de sua época, em todo o mundo. A criação de uma Faculdade de Farmácia foi marco divisor por implicar, necessariamente, no cultivo regular da Botânica, mesmo que inicialmente calcado no ensino e organização de coleções de apoio.

\section{PERÍODO PRÉ-ACADÊMICO}

Situada no centro geográfico do Rio Grande do $\mathrm{Sul}^{8}$, próximo ao divisor de águas entre as bacias dos rios Jacuí e Ibicuí, a cidade de Santa

5 MARCHIORI, J.N.C.; NOAL FILHO, V.A. Santa Maria: relatos e impressões de viagem. Santa Maria: Ed. da UFSM, 1997. p. 274.

6 "A explosão de escolas públicas e particulares começou no início do século XX e foi crescendo sem parar no decorrer dos anos, tornando a cidade o maior centro estudantil do interior do Estado, em relação ao número de seus habitantes. Por essa circunstância, Santa Maria ficou conhecida como Metrópole Escolar do Rio Grande" (BEBER, C.C. Santa Maria 200 anos: História da Economia do Município. Santa Maria: Pallotti, 1998. p. 14).

7 O nome original da instituição de ensino era "Faculdade de Farmácia e Odontologia de Santa Maria". Como o curso de Odontologia não foi oficializado em 1934, restou o de Farmácia, que pode ser considerado como o verdadeiro núcleo inicial da UFSM.

8 "Cidade coração do Rio Grande", aliás, é um dos epítetos atribuídos ao município (e cidade) de Santa Maria.
Maria se encontra em plena Depressão Central gaúcha e ao pé da Serra Geral, cadeia montanhosa que divide o Estado em duas regiões distintas sob os pontos de vista fisiográfico e vegetacional: a metade norte, com suas terras mais altas e originalmente revestidas por matas e campos em partes mais ou menos iguais; e a metade sul, marcada pelo predomínio do pampa ondulado. Esta situação privilegiada explica a diversidade florística e de vegetação observadas no município de Santa Maria, que inclui um largo trecho de Floresta Estacional nas encostas da dita Serra, com fragmentos de Floresta Mista em alguns pontos de contato com o Planalto Médio, além de vastos campos naturais, entremeados de matas ciliares e capões, nas planícies e coxilhas da Depressão Central.

Sob o ponto de vista histórico, a Depressão Central e o vale do Ibicuí sempre funcionaram como um "corredor" de acesso ao interior do Estado, tanto para os que partiam do litoral e laguna dos Patos, como aos vindos da fronteira oeste. Para ambos, Santa Maria encontra-se na metade da jornada.

Foi pelo rio Ibicuí, a partir de sua foz no rio Uruguai, que o Padre Roque González de Santa Cruz adentrou no Tape $^{9}$ em 1627, ele que foi o primeiro homem branco a pisar em terras do atual Rio Grande do Sul. Igualmente do oeste veio outro jesuíta - o Padre Adriano Formoso -, que no início da década seguinte ${ }^{10}$ foi o primeiro cura da redução de São Cosme e São Damião, fundada em área do atual sítio urbano de Santa

9 Primeira designação atribuída às terras do atual Rio Grande do Sul. Segundo Aurélio Porto, a palavra, que significa "povoação grande", servia para designar a “dilatada região confinada pelas serras do mar e Geral, a entestar no alto Jacuí e, pelo curso deste, até se lançar no mar". (PORTO, A. História das Missões Orientais do Uruguai. Porto Alegre: Selbach, 1954. v. 1. p. 79).

${ }^{10}$ A data de fundação de São Cosme e São Damião é motivo de controvérsia, havendo autores que apontam para o ano de 1632 (JAEGER, L.G. As primeiras reduções jesuíticas no Rio Grande do Sul. In: Terra Farroupilha. Porto Alegre: Selbach, 1937. p. 48) e, outros, para 1634 (TESCHAUER,C. História do Rio Grande do Sul. Porto Alegre: Selbach, 1918. v. 1. p. 131). 
Maria $^{11}$. A partir da fundação de Rio Grande (1737), na embocadura da laguna dos Patos, todo o espaço regional começou a pender para a esfera portuguesa, crescendo, a partir deste evento, o fluxo de viajantes no sentido lesteoeste. Os naturalistas do século XIX, entretanto, alcançaram Santa Maria por diferentes rotas.

O primeiro deles, certamente, foi Auguste de Saint-Hilaire ${ }^{12}$. Vindo das Missões, o grande botânico chegou à "Capela de Santa Maria" em 9 de abril de 1821, após descer a Serra pelo "caminho" de São Xavier ${ }^{13}$. Com apenas 24 anos de existência, o povoado compunha-se de "umas trinta casas" e "um par de ruas" com "lojas comerciais bem montadas". Em posição "bucólica", no dorso de uma "colina muito irregular", o francês anotou que de um lado se avistava "uma alegre planície, revestida de pastagens" e do outro a visão era "limitada por montanhas cobertas de florestas sombrias e espessas"..$^{14}$ Teria aquele outono proporcionado boas coletas em Santa Maria ao viajante francês? A resposta segue à espera de investigação, no Museu de História Natural de Paris ${ }^{15}$.

${ }^{11}$ BELTRÃO, R. Cronologia histórica de Santa Maria e do extinto município de São Martinho. Canoas:Tipografia Editora La Salle, 1979. p. 5-6.

${ }^{12}$ Natural de Órleans (4/10/1779), Augustin-FrançoisCésar Prouvensal de Saint-Hilaire faleceu em Turpinière (França), em 30/9/1853. Membro da embaixada do Conde de Luxemburgo, Saint-Hilaire chegou ao Brasil em $1 / 6 / 1816$, percorrendo, ao longo de seis anos, cerca de 2.500 léguas pelo interior do país. O material botânico reunido nestas viagens renderam-lhe notáveis publicações científicas, salientando-se a Flora Brasilica Meridionalis , obra que lhe abriu as portas da "Academia de Ciências" da França. Suas coletas de plantas brasileiras estimam-se em 30.000 exemplares, pertencentes a mais de 7.600 espécies.

${ }^{13}$ Do Planalto Médio, Saint Hilaire seguiu, aproximadamente, pelo divisor de águas entre os rios Jaguari e Toropi, na chamada Serra de São Xavier, cruzando, finalmente, por este último rio após descer a Serra, já na Depressão Central.

${ }^{14}$ SAINT-HILAIRE, A. de. Viagem ao Rio Grande do Sul. Brasília: Senado Federal, Conselho Editorial, 2002. p. 404).
Dois anos após a visita de Saint-Hilaire, chegava Friedrich Sellow ${ }^{16}$ a Santa Maria, na qualidade de naturalista do Museu Nacional do Rio de Janeiro. Vindo de Montevidéu, o botânico alemão entrou no Rio Grande do Sul por terras do atual município de Livramento, em 24 de março de 1823, passando, a seguir, por Santa Maria e São Martinho, a caminho de Porto Alegre $^{17}$. Morto por afogamento no rio Mucuri, em novembro de 1831, o desventurado naturalista não teve o tempo necessário para estudar o gigantesco acervo botânico por ele reunido, em viagens pelo Brasil e Uruguai, motivo pelo qual o seu nome ainda é pouco conhecido, até mesmo nos círculos acadêmicos. Há que salientarse, todavia, que Sellow é o coletor de espéciesnovas mais citado na monumental Flora Brasiliensis $^{18}$, superando neste aspecto até mesmo Saint-Hilaire ${ }^{19}$. Infelizmente, suas exsicatas acabaram dispersas em numerosos herbários, na Europa, Estados Unidos, Brasil e Chile ${ }^{20}$, o que dificulta, sobremaneira, uma avaliação acerca do material coletado em Santa Maria.

${ }^{15}$ Abreviado pela letra "P", segundo o Index Herbariorum, o Herbário de Paris (Muséum National d'Histoire Naturelle, Laboratoire de Phaneroghamie) é instituição de renome mundial e guarda a maioria das coletas de Saint-Hilaire.

${ }^{16}$ Friedrich Sellow nasceu em Potsdam (12/3/1789), Alemanha, e faleceu no Brasil, aos 42 anos de idade.

${ }^{17}$ MARCHIORI, J.N.C; DURLO, M.A. Friedrich Sellow e sua contribuição para as Ciências Naturais. Ciência \& Ambiente, Santa Maria, n. 16, p. 29-50, 1998.

${ }^{18}$ Iniciada por Martius e concluída por Urban, a Flora Brasiliensis inclui a descrição de milhares de espécies coletadas por Sellow.

${ }^{19}$ Somente para o Botanisches Museum (Berlim), Sellow enviou 51.480 exsicatas, pertencentes a mais de 11.700 espécies botânicas; boa parte deste material perdeu-se, infelizmente, no incêndio ocorrido no Museu, ao final da Segunda Guerra Mundial.

${ }^{20}$ Apenas no Herbário de Santiago do Chile encontram-se mais de 120 "tipos" de Mirtáceas, entre espécies e variedades, coletadas por Sellow no Brasil e Uruguai (KAUSEL, E. Los tipos de Mirtaceas extrangeras conservados en el Herbario de Santiago. Revista Universitaria, Universidad Católica de Chile, Santiago, v. 35 , n. 1, p. 135-146, 1950). Resta informar que muitos destes binômios caíram, com o tempo, em sinonímia. 
A estes dois cientistas seguiram-se Arsène Isabelle $^{21}$ e Robert Avé-Lallemant ${ }^{22}$. Mesmo não sendo botânicos, os seus nomes merecem, ao menos, um breve comentário, pois deixaram relatos que figuram entre os mais notáveis da estante sul-rio-grandense de viajantes.

Com as limitações de um naturalista-amador, Isabelle chegou a Santa Maria a $1^{\circ}$ de março de 1830. Vindo das Missões, o francês desceu a Serra Geral por um caminho mais a oeste do que o escolhido por Saint-Hilaire e que chegava ao "corredor central", anteriormente mencionado, nos arredores de São Francisco de Assis. Além de coletas botânicas, que se perderam com o tempo, Isabelle foi um dos pioneiros no registro de "troncos de árvores fósseis" na região de Santa Maria ${ }^{23}$.

Médico de notável cultura, Avé-Lallemant viajou pelo Rio Grande do Sul em 1858, após muitos anos de residência no Rio de Janeiro. Um de seus objetivos era conhecer pessoalmente o grande Aimé Bonpland, amigo e companheiro de viagem de Alexander von Humboldt à América do Sul, que vivia em São Borja, na época, e possuía uma estância na província argentina de Corrientes, próximo à atual Paso de los Libres. O relato da viagem de Avé-Lallemant ao Estado $^{24}$ inclui as mais belas referências já

${ }^{21}$ Autor de uma "Viagem ao Rio Grande do Sul (1833 1834)", Arsène Isabelle nasceu no Havre (França, 1807) e faleceu por suicídio em sua terra natal, a 13/1/1888. Comerciante por profissão, mas com acentuado gosto pelas ciências naturais, Isabelle partiu para a América do Sul em 1830, estabelecendo-se inicialmente em Buenos Aires e, mais tarde, em Montevidéu.

${ }^{22}$ Apesar do acento francês do nome, Robert AvéLallemant nasceu em Lübeck (Alemanha), em 1812. Após estudos superiores em Berlim e Paris, doutorouse na Universidade de Kiel (1837), viajando no ano seguinte para o Brasil. Durante 17 anos trabalhou como médico no Rio de Janeiro e, após breve retorno à terra natal, deu início às longas e proveitosas excursões ao interior do Brasil, que lhe renderam material para importantes relatos de viagem.

${ }^{23}$ MARCHIORI, J.N.C. Arsène Isabelle. Ciência \& Ambiente, Santa Maria, n. 13, p. 55-72, 1996.

${ }^{24}$ AVÉ-LALLEMANT, R. Viagem pelo sul do Brasil no ano de 1858. Rio de Janeiro: Instituto Nacional do Livro, $1953.398 \mathrm{p}$. escritas sobre o entorno de Santa Maria e, apesar de não ser do ramo, também registra preciosas descrições de cunho fitogeográfico, como a do extinto pinhal de Itaara, ao norte da cidade ${ }^{25}$.

Integrantes da "Primeira Viagem Regnelliana"26 Lindman $^{27}$ e Malme ${ }^{28}$ coletaram plantas em duas oportunidades na região: de 4 a 23 de março de 1893, em sua viagem de Cachoeira do Sul a Ijuí (via Silveira Martins), e de 27 de abril a 7 de maio do mesmo ano, no retorno de Ijuí a Porto Alegre, via São Martinho. Integrantes do corpo científico do Museu de Estocolmo, os dois botânicos viram-se forçados a abandonar o Estado às pressas, por motivos de segurança, devido à revolução de 1893. Malme retornou ao Rio Grande do Sul (e a Santa Maria) em outubro de 1901, para novas coletas botânicas, permanecendo no Estado até abril de $1902^{29}$. Lindman, embora não tenha retornado, deixou-nos uma das obras fundamentais sobre a vegetação sul-rio-grandense. Publicada originalmente em sueco (1900), A vegetação no Rio Grande do $\mathrm{Su}^{30}$ inclui importantes referências

${ }^{25}$ Com admirável acerto, Avé-Lallemant usou os termos pinetum e palmetum para definir o pinhal de Itaara, com base na coexistência, na estrutura da vegetação, de uma conífera (Araucaria angustifolia), espécie típica da Floresta Mista, e de uma palmeira (Syagrus romanzoffiana), elemento imigrado da Floresta Estacional adjacente.

${ }^{26}$ Anders Fredrick Regnell veio ao Brasil em busca de um clima mais quente, com vistas à cura da tuberculose, e atuou como médico em Poços de Caldas (Minas Gerais) por quase 50 anos. Regnell foi um mecenas da Botânica, pois foi graças a seu apoio (Fundo Regnelliano) que Lindman e Maime, entre outros cientistas escandinavos, puderam vir ao Brasil.

${ }^{27}$ Carl Axel Magnus Lindman nasceu em Halmstad (sul da Suécia), em 6/4/1856, e faleceu em Estocolmo, em 21-6-1928. Doutor em Botânica pela famosa Universidade de Uppsala (1886), foi pesquisador do Museu Nacional de Estocolmo.

${ }^{28}$ Gustav Oskar Andersson Malme nasceu em Stora Malm (Suécia), em 24/10/1864, e faleceu em Estocolmo, em $5 / 3 / 1937$. Doutor pela Universidade de Uppsala, notabilizou-se como taxonomista vegetal.

${ }^{29}$ BAPTISTA, L.R. de M. Gustav Malme e a flora do Rio Grande do Sul. Ciência \& Ambiente, Santa Maria, n. 13, p. 99-104, 1996.

${ }^{30}$ Traduzida para o português por Alberto Löfgren, a obra teve sua primeira edição portuguesa em 1906 (Livraria 


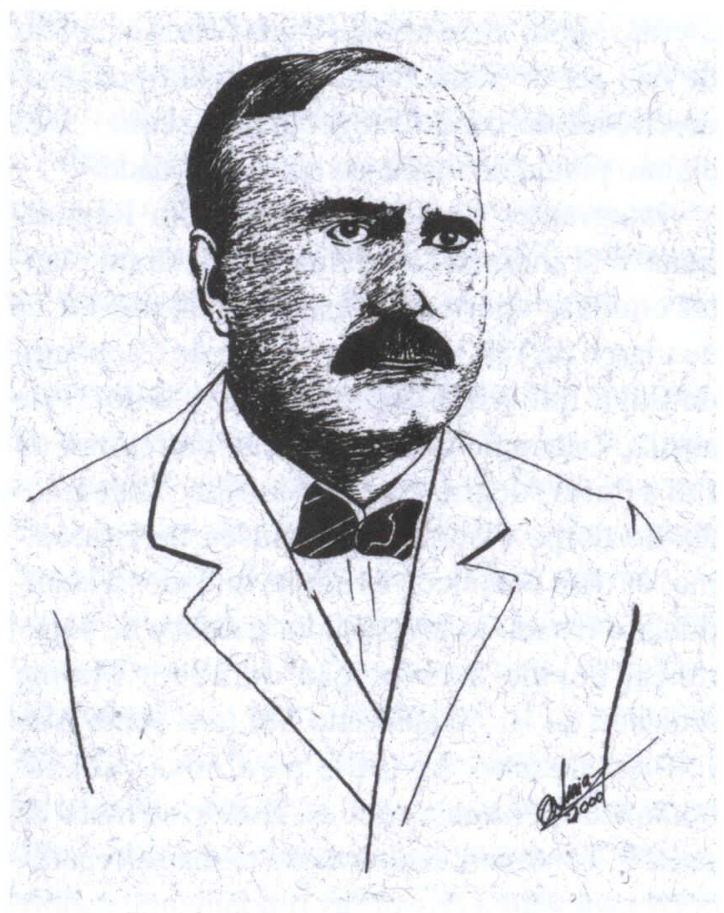

FIGURA 1 - Dr. Guilherme Rau, em desenho de Antônio Isaia. (Fonte: Isaia, A. Os fascinantes caminhos da Paleontologia, p. 39).

sobre os arredores da cidade, enriquecidas com ilustrações de um fragmento florestal em Silveira Martins e dos morros de Santa Maria.

Ao contrário dos viajantes anteriormente comentados, o Dr. Wilhelm Rau (Figura 1) ${ }^{31}$ veio para ficar, em setembro de 1910, depois de haver clinicado em Porto Alegre e Caçapava do $\mathrm{Sul}^{32}$. Médico oculista e otorrinolaringologista

Universal de Echenique Irmãos \& Cia., Porto Alegre). A segunda, de 1974, foi uma co-edição entre a Editora da Universidade de São Paulo e a Livraria Itatiaia.

${ }^{31}$ Natural de Ludwigshafen, no Palatinado, Alemanha (30/ 7/1874), Wilhelm Rau faleceu em Santa Maria (11/5/ 1953). Embora médico, por formação, ele tinha uma acentuada inclinação pela pesquisa em ciências naturais, demonstrada em importantes contribuições à Paleontologia, Geologia e Botânica do Rio Grande do Sul.

${ }^{32}$ Em sua Cronologia Histórica de Santa Maria (Op. cit., p. 459-460), Romeu Beltrão informa que o Dr. Guilherme Rau abriu consultório na cidade em 2 de setembro de 1910, clinicando em Santa Maria até falecer, em 11/ $5 / 1953$.

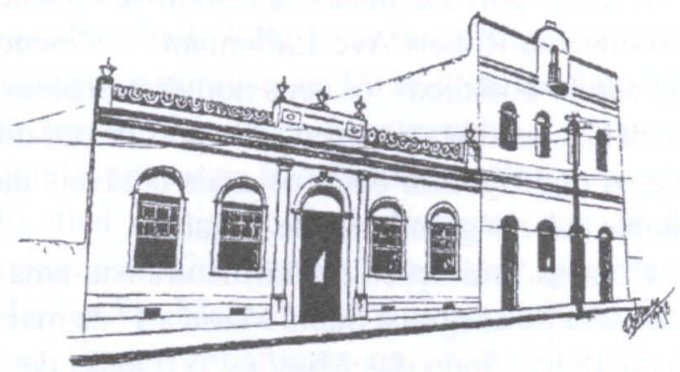

FIGUKA 2 - Sede inicial da raculdade de rarmacia de Santa Maria (casarão térreo, à Av. Rio Branco), em desenho de Antônio Isaia.

de formação européia ${ }^{33}$, ele era extremamente modesto e de vasta cultura, com "profundos conhecimentos em Assiriologia e Egiptologia", além de "naturalista nato" 34 . Provam esta vocação os seus estudos sobre plantas fósseis do carvão sul-rio-grandense, que incluem descrições de duas espécies novas (Cedroxylon canoasense $\mathrm{Rau}^{35}$ e Dadoxylon (Araucarioxylon) butiense $\mathrm{Rau}^{36}$ ), bem como suas coletas e estudos sobre a flora regional. Sobre este ponto, aliás, cabe destacar que as exsicatas de Rau foram incorporadas ao Herbário da Faculdade de Farmácia (HFFSM), precursor do atual Herbário do Departamento de Biologia (SMDB), da UFSM.

Reconhecido em vida pelo valor de suas contribuições à ciência, Guilherme Rau foi homenageado pela Universidade de Tübingen com o título de Doutor Honoris Causa. O gênero Rauisuchus e a espécie Hoplitosuchus raui, designados por Friedrich von Huene, foram também criados em homenagem ao grande natura-

${ }^{33}$ Cursou as universidades de Munique, Berlim e Bonn (BELTRÃO, 1979. Op. cit., p. 460).

${ }^{34}$ BELTRÃO, 1979. Op. cit., p. 460.

${ }^{35}$ RAU, W. Cedroxylon canoasense, una madera fósil nueva del Río Grande del Sud. Revista Sudamericana de Botanica, Montevideo, v. 1, n. 3, p. 65-68, 1934.

${ }^{36}$ RAU, W. Dadoxylon (Araucarioxylon) butiense $\mathrm{n} . \mathrm{sp}$. Ein bertrag zur entwicklung der holzstruktur der Palaeozoischen Koniferen Rio Grande do Sul. Revista Sudamericana de Botânica, Montevideo, v. 1, n. 6, p. 169-172, 1933. 
lista, que viveu modestamente em Santa Maria por quase 43 anos. Por esta longa e produtiva vida na cidade, Guilherme Rau não pertence, exclusivamente, ao período inicial da Botânica, ora em análise, motivo pelo qual o seu nome volta a ser comentado mais adiante.

\section{PERÍODO ACADÊMICO}

A criação da Faculdade de Farmácia ${ }^{37}$, como comentado anteriormente, mudou e impulsionou a trajetória da Botânica em Santa Maria (Figura 2). Surgia, por conseqüência, a necessidade de um professor específico para a disciplina, a fim de atender aos encargos didáticos e dar início à organização de coleções botânicas, necessárias tanto ao ensino como à pesquisa.

O desenvolvimento da ciência, todavia, foi muito modesto nas primeiras décadas - e não poderia ser de outro modo, cabe frisar -, tendose em vista o caráter particular da instituição e as limitações decorrentes do isolamento em relação a outros centros de cultura, aspecto sumamente relevante, sobretudo naqueles tempos, marcados por meios de comunicação precários.

Zózimo Lopes dos Santos, em conhecida obra sobre o ensino farmacêutico em Santa Maria $^{38}$, lista o corpo docente da Faculdade no primeiro ano de funcionamento (1932) e as respectivas áreas de atuação: Dr. Amaury Appel Lenz (Química Orgânica e Biológica); Dr. Eduardo Pinto de Morais (Botânica Aplicada à Farmácia); Dr. Francisco Mariano da Rocha (Zoologia e Parasitologia); e Dr. Valentim Fernandez (Física Aplicada à Farmácia). Cabe destacar que o idealizador, fundador e primeiro diretor desta Faculdade foi o Dr. Francisco Mariano da Rocha ${ }^{39}$,

\footnotetext{
${ }^{37}$ Não custa repisar que a Faculdade fundada em 1931 era de Farmácia e Odontologia. Como este último curso não foi oficializado naquela oportunidade, a instituição é, aqui, denominada, tão simplesmente, como "Faculdade de Farmácia".

${ }^{38}$ SANTOS, Z.L. dos. Histórico (1931-1961). In: 60 anos de ensino farmacêutico em Santa Maria, RS. Santa Maria: Imprensa Universitária/UFSM, 1991. p. 31-41.

${ }^{39}$ Natural de Pelotas (8/8/1887), veio para Santa Maria em 1912, atuando na cidade como médico até a sua morte $(4 / 7 / 1945)$.
}

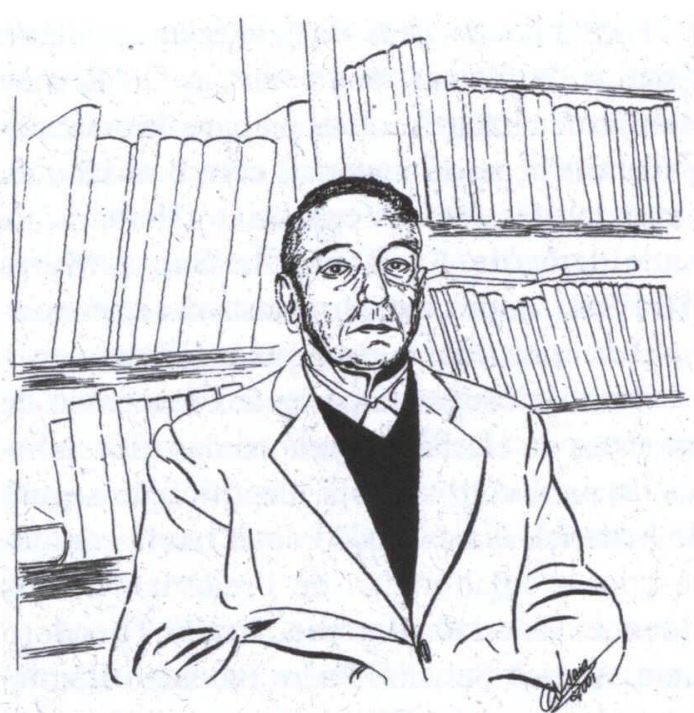

FIGURA 3 - Dr. Romeu Beltrão, em desenho de Antônio Isaia (Fonte: Isaia, A. Os fascinantes caminhos da Paleontologia, p 53).

seguido, no cargo, pelos doutores José Mariano da Rocha Filho, futuro fundador da UFSM, e Hélios Homero Bernardi ${ }^{40}$.

Nos anos de 1935 e 1936, o Dr. Guilherme Rau, anteriormente apresentado, atuou como professor de Botânica na Faculdade ${ }^{41}$. A partir de 1938, Romeu Beltrão (Figura 3) assumiu a disciplina de Botânica Aplicada à Farmácia, a qual lecionou por mais de 30 anos, tornando-se "Catedrático" com o tempo. Dentre os "Instrutores de Ensino" da disciplina, passaram, entre outros, o Dr. Isidro Agostinho Gai ${ }^{42}$, Olívia Viero Prass e Therezinha Isaia Paviani ${ }^{43}$.

\footnotetext{
${ }^{40}$ Farmacêutico, sucedeu José Mariano da Rocha Filho como segundo reitor da Universidade Federal de Santa Maria.

${ }^{41}$ BELTRÃO, 1979. Op. cit. p. 460.

${ }^{42}$ Natural de Silveira Martins (4/5/1920), formou-se em Medicina pela Universidade do Rio Grande do Sul (1944) e realizou especialização em Cirurgia GastroIntestinal no famoso Columbus Hospital (Chicago), nos anos de 1946 e 1947.

${ }^{43}$ Em artigo publicado no $1^{\circ}$ Boletim do Instituto de Ciências Naturais da Universidade de Santa Maria, a autora informa que, em 1962, era "Instrutora de Ensino" de Botânica Aplicada à Farmácia, cujo Professor Catedrático era o Dr. Romeu Beltrão.
} 
Face à necessidade de manter uma coleção didática de plantas medicinais, o Dr. Romeu Beltrão deu início à coleta, preparo de exsicatas e identificação do material, com o auxílio de outros professores. A criação do Herbário da Faculdade de Farmácia de Santa Maria (HFFSM), neste contexto, mostrou-se necessária para armazenar a crescente coleção.

Outra iniciativa importante foi o envio de exsicatas do Herbário a renomados especialistas do país, com vistas à identificação segura do material. Na execução desta tarefa contouse com a colaboração de Frederico Carlos Hoehne, Graziela Barroso, Irmão Theodoro Luiz, Alarich Schultz, Padre Balduíno Rambo e, inclusive, de Diego Legrand, famoso mirtólogo uruguaio. Anos mais tarde, Romeu Beltrão destacou a contribuição "eficiente" e "desinteressada" prestada por Balduíno Rambo, pois ele, sozinho, identificou "mais de 2000 exsicatas" do Herbário, ao longo de "quase seis anos". 44

Em 4 de dezembro de 1948, a Faculdade de Farmácia de Santa Maria foi incorporada à Universidade do Rio Grande do Sul, permanecendo nessa situação até a criação da Universidade de Santa Maria, em $1960^{45}$.

$\mathrm{Na}$ organização da Universidade, Romeu Beltrão foi nomeado diretor do Instituto de Ciências Naturais, em março de 1962, permanecendo no cargo até a aposentadoria, em 1969. Com acentuada predileção pela pesquisa, Beltrão foi personalidade singular na Santa Maria de sua época. Verdadeiro polímata, misto de historiador, cronista e cientista, ele deixou contribuições de perene valor, em todos os campos em que atuou.

Como historiador, basta citar a sua Cronologia Histórica, obra até hoje indispensável ao

${ }^{44}$ BELTRÃO, R. Homenagem ao Botânico desaparecido. Boletim do Instituto de Ciências Naturais da Universidade de Santa Maria, Santa Maria, n. 1, p. 89-94, 1962.

${ }^{45}$ BEBER, 1998. Op. cit., p. 24.

${ }^{46}$ BELTRÃO, R. O vanguardeiro de Itororó. Santa Maria: Câmara Municipal de Vereadores, 1998. 222p. conhecimento do passado santa-mariense. Como cronista, colaborou assiduamente nos jornais da cidade, com artigos sobre plantas, paleontologia, história, música e personalidades da região. É o caso, entre outros, dos 51 artigos publicados em A Razão sobre o Coronel João Niederauer Sobrinho, resgatados em livro póstumo (1998), patrocinado pela Câmara Municipal de Vereadores de Santa Maria ${ }^{46}$.

Para as ciências da natureza, finalmente, Beltrão foi o editor e principal colaborador do Boletim do Instituto de Ciências Naturais, periódico que, apesar de sua curta existência (teve apenas três números), depõe favoravelmente sobre a atividade de pesquisa nos primórdios da Universidade. No campo da Botânica, merecem destaque dois alentados trabalhos de Beltrão sobre a flora fanerogâmica de Santa Maria, vindos a lume em $1962^{47}$ e $1965^{48}$ no referido Boletim. Cabe salientar que este esforço pioneiro não poderia ser realizado, com sucesso, sem a prévia identificação das exsicatas por especialistas, comentada anteriormente. No total, foram listadas 1073 espécies de fanerógamas para o município, distribuídas em 113 famílias botânicas. Apesar de alguns óbices terminológicos e das numerosas espécies agregadas posteriormente à flora regional, estas duas publicações persistem como basilares para estudos florísticos no centro do Estado.

A criação de novos cursos, como os de Agronomia (1961) e História Natural (1965), aumentou significativamente o número alunos e diversificou as disciplinas na área de Botânica, justificando a entrada de novos professores. O convívio com profissionais de outras áreas foi outro aspecto benéfico decorrente desta expansão,

${ }^{47}$ BELTRÃO, R. Flórula fanerogâmica do município de Santa Maria, RS, Brasil (Primeiro Catálogo). Boletim do Instituto de Ciências Naturais da Universidade de Santa Maria, Santa Maria, n. 1, p. 3-63, 1962.

${ }^{48}$ BELTRÃO, R. Flórula fanerogâmica do município de Santa Maria, RS, Brasil (Primeiro Suplemento). Boletim do Instituto de Ciências Naturais da Universidade Federal de Santa Maria, Santa Maria, n. 2, p. 115-151, 1965. 


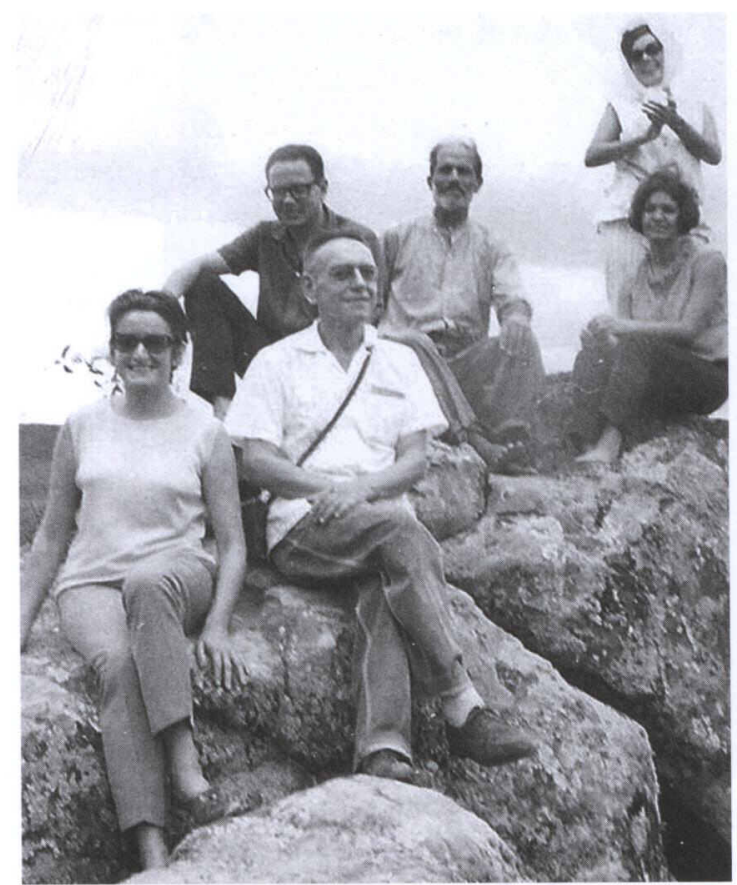

FIGURA 4 - Dr. Romeu Beltrão (sentado, em primeiro plano), Maria Helena Cechella Achutti (à esquerda), Vanoli José Xavier Lopes (atrás), Amélia Moema Veiga Lopes (em pé) e outros dois excursionistas, em São Martinho da Serra.

uma vez que a Botânica permeia o ensino e a pesquisa em diversos setores do conhecimento (Figura 4).

No início, participaram do Instituto as seguintes professoras: Maria Marli Pignataro Nicolini (Farmacêutica, Botânica Agrícola); Therezinha Isaia Paviani (Farmacêutica, Anatomia de Plantas); Thereza Grassioli (Licenciada em História Natural, Anatomia e Morfologia de Plantas); e Maria Helena Cechella Achutti (Farmacêutica, Anatomia e Morfologia de Plantas).

A partir de 1965, novos professores foram admitidos ao Instituto de Ciências Naturais: Amélia Moema Veiga Lopes (Farmacêutica, Botânica Aplicada à Farmácia); Zilma Baldissera (Licenciada em História Natural, Sistemática de Vegetais Inferiores); Santo Masiero (Eng. Agrônomo, Botânica Sistemática); Vanoli José Xavier Lopes (Eng. Agrônomo, Anatomia e Morfologia de Plantas); José
Carlos Funck Pignataro (Eng. Agrônomo, Fisiologia Vegetal); Vítor Hugo da Silva e Souza (Farmacêutico, Fisiologia Vegetal); Vera Lúcia Bender Dellaméa (Licenciada em História Natural, Sistemática de Vegetais Superiores); Adelino Alvarez Filho (Eng. Agrônomo, Botânica Agrícola). Além destes professores, também contribuíram para o crescimento da Botânica os seguintes servidores técnicos de laboratório: Olga S. de Vargas (Técnicas usuais em Taxonomia Vegetal - Herbário); Antonieta Isaia Rosa e Ertile Löebler (Técnicas usuais em Anatomia Vegetal).

Em 1969, com o desmembramento dos antigos institutos, a área de Botânica foi incorporada ao Departamento de Biologia, juntamente com os setores de Genética e Zoologia. O Herbário HFFSM, igualmente transferido para o novo Departamento, foi registrado no Index Herbariorum em 1978, com a sigla SMDB (Santa Maria Departamento de Biologia), com a qual é reconhecido em todo o mundo. O Herbário conta, atualmente, com cerca de 13.500 exsicatas, distribuídas nas seguintes coleções: Balduino Rambo, Guilherme Rau, Romeu Beltrão, Anacreonte Araújo, Therezinha Isaia Paviani, Adelino Alvarez Filho, Ismar Leal Barreto, Amélia Moema Veiga Lopes, Vera Bender Dellaméa, Zilma Baldissera, Luiz Zago Machado e Renato Aquino Záchia.

Após a formação do Departamento de Biologia, seguiu aumentando o número de cursos na instituição por ele atendidos. É o caso da Engenharia Florestal, cuja primeira turma, de 40 alunos, ingressou na Universidade em março de 1971. Com diversas disciplinas da área de Botânica em seu currículo, apenas as da área básica foram alocadas no Departamento de Biologia (Morfologia Vegetal, Botânica Sistemática, Fisiologia Vegetal), ficando as restantes no Departamento de Engenharia Agrícola e Florestal (Centro de Ciências Rurais), precursor do atual Departamento de Ciências Florestais. Em conseqüência desta situação, criou-se um segundo núcleo de estudos botânicos na Universida- 


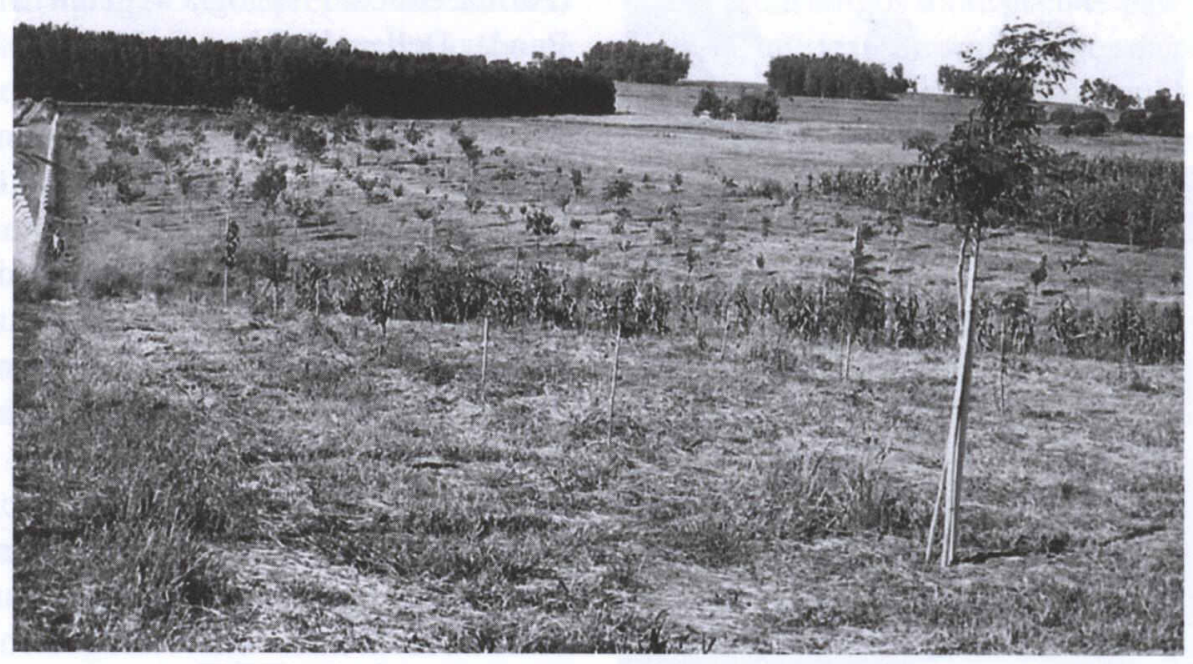

FIGURA 5 - O Jardim Botânico da UFSM, em seus primórdios.

de, cujo histórico será abordado mais adiante.

$\mathrm{O}$ aumento no número de cursos da instituição a serem atendidos pelo Departamento de Biologia justificou a admissão de novos professores e pesquisadores: Francisca Marlene Silveira Vianna (Licenciada em História Natural, Sistemática de Vegetais Inferiores); Vera Lúcia Siqueira (Licenciada em História Natural, Anatomia e Morfologia de Plantas); Julieta Gisselda Dellazzana (Licenciada em História Natural, Sistemática de Vegetais Inferiores); e Gilberto Antônio Freitas de Moraes (Eng. Agrônomo, Fisiologia Vegetal). No corpo de servidores técnicos, foram admitidos Elcy Baptistella (Técnicas usuais em Anatomia Vegetal) e Vanir Scott Bitencourt (Laboratório de Fisiologia Vegetal).

O novo corpo docente herdou o entusiasmo e o interesse de seus antecessores, no tocante ao ensino, pesquisa e extensão. Após muito trabalho e superação de obstáculos, um sonho antigo e ambicioso converteu-se em realidade: o Jardim Botânico da UFSM (Figura 5) foi solenemente inaugurado em 03/12/1981, convertendo-se, a partir deste momento, em fonte de significativo avanço institucional. Localizado na zona oeste do Campus (setor 8 da zona rural), o Jardim Botânico possui uma área de aproximadamente 14 hectares e, atualmente, um acervo de 844 espécies, distribuídas em 13 hectares (Figura 6). Cabe registrar que os professores Santo Masiero, Amélia Moema Veiga Lopes, James Silveira Pizzarro, Vanoli José Xavier Lopes, Vera Lúcia Bender Dellaméa, Adelino Alvarez Filho, Juarez Martins Hoppe e Luiz Galvão, sob a presidência do primeiro, foram os nomeados pela Reitoria para administrar a implantação e o funcionamento inicial do Jardim Botânico.

Com a aposentadoria dos primeiros professores, ingressaram no corpo docente do Departamento de Biologia: Sônia Maria Eisinger (Bióloga, Botânica Agrícola); Jumaida Maria Rosito (Bióloga, Sistemática de Angiospermas); Elci Henz Franco (Licenciada em História Natural, Fisiologia Vegetal); Thais Scotti do Canto-Dorow (Bióloga, Sistemática de Angiospermas); Mara Ritter (Bióloga, Sistemática de Angiospermas); João Fernando Prado (Biólogo, Sistemática de Vegetais Avasculares); Renato Aquino Záchia (Biólogo, Sistemática de Angiospermas); Juçara Teresinha Paranhos 


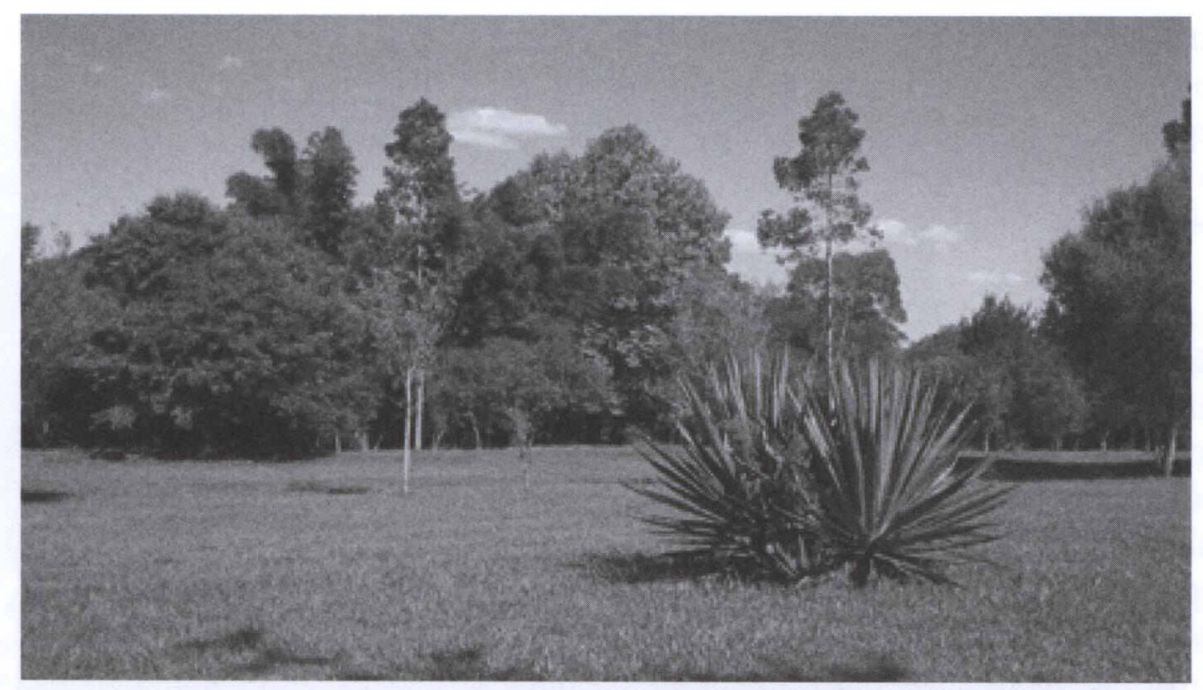

FIGURA 6 - Vista parcial do Jardim Botânico da UFSM em 2011.

(Eng. Agrônoma, Fisiologia Vegetal); Sylvio Bidel Dornelles (Eng. Agrônomo, Morfologia e Anatomia de Plantas); Fernando Teixeira Nicoloso (Eng. Agrônomo, Fisiologia Vegetal); Maria Angélica Oliveira (Bióloga, Sistemática de Vegetais Avasculares); e João Marcelo Santos de Oliveira (Biólogo, Morfologia e Anatomia de Plantas). No corpo de servidores técnicos, registra-se o ingresso de Bernadete Panno (Técnicas usuais em Taxonomia Vegetal Herbário), Marisa Binotto Abbad (Técnicas usuais em Anatomia Vegetal) e Tânia Boucinha Vianna (Laboratório de Fisiologia Vegetal).

Nas últimas décadas, a Botânica teve avanços consideráveis, graças ao aporte recebido de áreas correlatas, notadamente da Biologia Molecular, Cladística e Citogenética. No setor de Botânica do Departamento de Biologia da UFSM destacam-se, atualmente, pela cooperação e parceria em projetos, os professores Élgion Lúcio da Silva Loreto (Biólogo, Biologia Molecular), Lenira Maria Nunes Sepel (Bióloga, Biologia Molecular) e Solange Bosio Tedesco (Bióloga, Citogenética Vegetal).

$\mathrm{O}$ crescimento do ensino e pesquisa em Botânica ganhou reforço, no início de 2010, com a implantação do curso de Mestrado em Agrobiologia, atualmente com três linhas de pesquisa: Interações organismos-ambientes; Propagação, desenvolvimento e metabolismo vegetal; e Caracterização de espécies vegetais em ambiente natural e/ou modificado. A criação deste curso de Pós-Graduação representa significativo avanço ao crescimento e qualificação da pesquisa botânica em Santa Maria, consolidando um objetivo perseguido por várias gerações de professores (Figura 7).

Por fim, retoma-se um tema apenas esboçado anteriormente: a existência de um segundo núcleo de ensino e pesquisa em Botânica na UFSM, decorrente da criação do curso de Engenharia Florestal. Trata-se de um grupo relativamente pequeno, com apenas dois professores e quatro disciplinas direcionadas à profissão de Engenheiro Florestal: Anatomia da Madeira, Dendrologia, Fitogeografia e Fitossociologia.

As primeiras turmas de alunos tiveram aulas de Anatomia, Fitogeografia e Dendrologia com professores de outras disciplinas; no caso da Fitossociologia, sua inclusão no currículo é mais recente. Cabe destacar, nos primórdios do curso, as aulas de Fitogeografia ministradas por Franz Andrae, Engenheiro Florestal austríaco de amplo conhecimento e experiência profissional. $\mathrm{Na}$ falta de professor habilitado, as duas primeiras turmas tiveram aulas de Anatomia da Ma- 


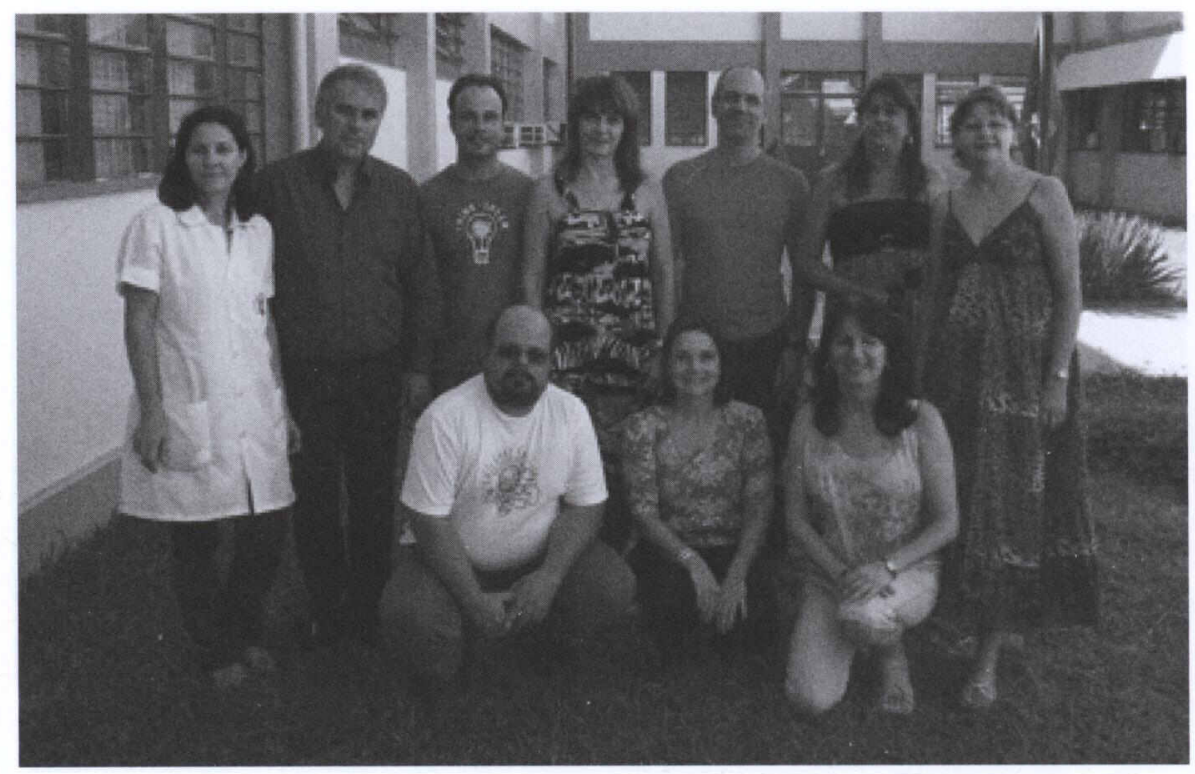

FIGURA 7 - Servidores do Setor de Botânica (Departamento de Biologia - UFSM), em 2011. Atrás, da esquerda para a direita: Bernadete Panno, Sylvio Bidel Dornelles, João Marcelo Santos de Oliveira, Jumaida Maria Rosito, Fernando Teixeira Nicoloso, Juçara Teresinha Paranhos e Sônia Maria Eisinger. À frente, da esquerda para a direita: Renato Aquino Záchia, Thais Scotti do Canto-Dorow e Maria Angélica Oliveira.

deira com José Lívio Gomide, professor da Universidade Federal de Viçosa (Minas Gerais).

O primeiro professor contratado especialmente para o setor foi o Eng. Florestal Solon Jonas Longhi (Figura 8), em 1975, para as aulas de Dendrologia, Fitogeografia e, a partir do segundo semestre de 2005, também de Fitossociologia. Em 1976, ingressou no Departamento o Eng. Florestal José Newton Cardoso Marchiori (Figura 8), responsável, desde então, pela disciplina de Anatomia da Madeira e, a partir do segundo semestre de 1990, também pela de Fitogeografia.

O Herbário do Departamento de Ciências Florestais (HDCF) foi criado em 1980, como suporte indispensável ao ensino e pesquisa. Embora ainda não registrado no Index Herbariorum, a coleção já soma mais de 11.000 exsicatas, sobretudo de espécies lenhosas, estando muito bem conservada em caixas metálicas fabricadas especialmente para a finalidade. O Herbário conta, atualmente, com prédio próprio (Figura 8) e salas para o armazenamento da coleção, bem como para o preparo de material e estudos.
No caso da Anatomia da Madeira, a coleção produzida em 35 anos de trabalho compõe um acervo de milhares de lâminas, que inclui a maioria das espécies lenhosas da flora sulina, bem como exemplares representativos de outras regiões do Brasil, da América do Sul e de outras partes do mundo.

Em janeiro de 2005 foi lançado o primeiro número da revista "Balduinia" pelo Herbário do Departamento de Ciências Florestais da UFSM, destinada a publicar artigos científicos sobre a flora sul-brasileira nas áreas de Taxonomia Vegetal, Florística, Fitogeografia e Anatomia da Madeira. Este objetivo, aliás, está expresso no dístico latino escolhido para a revista - Pro Austro-Brasiliae Flora -, que aparece subscrito ao símbolo do periódico: um ramo estilizado de Mutisia coccinea St.-Hil., obra artística de Leonardo Paz Deble. A edição de 27 números, até o momento (média de 4 por ano), demonstra que a revista vingou; os artigos publicados, por sua vez, falam por si do compromisso tenazmente perseguido. 


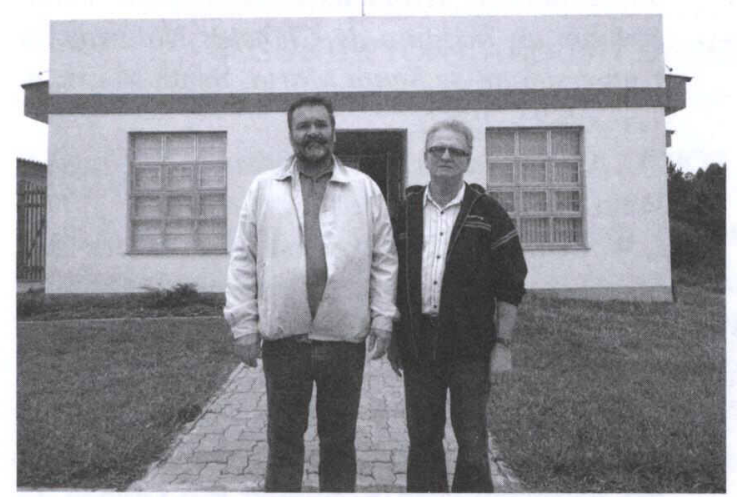

FIGURA 8 - José Newton Cardoso Marchiori e Solon Jonas Longhi (à direita), frente ao novo prédio do Herbário do Departamento de Ciências Florestais da UFSM.

Mais antiga e dependente do Departamento de Ciências Florestais da UFSM, a revista "Ciência Florestal" também publica, desde 1991, boa parte da produção científica gerada por seus professores e alunos, incluindo numerosos trabalhos em Fitossociologia e Anatomia da Madeira, entre outros campos do conhecimento.

Com a criação do Curso de Pós-Graduação em Engenharia Florestal (1990), o ensino e a pesquisa receberam forte estímulo, demonstrado no crescimento em número e qualidade das publicações enviadas a revistas, bem como na volumosa estante de suas dissertações e teses de doutorado.

\section{CONSIDERAÇÕES FINAIS}

Ao se refletir sobre a História da Botânica em Santa Maria, vê-se que a semente plantada há muitas décadas - e carinhosamente cuidada por sucessivas gerações de professores e pesquisadores -, alcança, finalmente, a sua maturidade nos dias em que vivemos e, como árvore frondosa no campus da UFSM, se encontra em plenas condições para abrigar e estimular, nos jovens estudantes, o amor pela Scientia Amabilis.

Além da dedicação dos professores - uma constante ao longo do tempo - há que se ressaltar o benefício ao ensino e à pesquisa trazidos pelo aperfeiçoamento do corpo docente em cursos de mestrado, doutorado e pós-doutorado, bem como o forte estímulo exercido pelas bolsas de pesquisa a muitos professores e alunos, tanto de Graduação (Iniciação Científica) como de Pós-Graduação.

O progresso tecnológico, por sua vez, que trouxe acesso instantâneo à informação, eliminou, em boa parte, os prejuízos antigamente vivenciados por instituições mais distantes dos grandes centros. A facilidade de acesso à bibliografia, a fototipos e a outros materiais indispensáveis à investigação botânica, que atualmente são disponibilizados pela informática, também apontam para uma crescente qualificação do ensino e pesquisa em nosso meio.

\section{REFERÊNCIAS BIBLIOGRÁFICAS}

AVÉ-LALLEMANT, R. Viagem pelo sul do Brasil no ano de 1858. Rio de Janeiro: Instituto Nacional do livro, 1953. 398 p.

BAPTISTA, L.R. de M. Gustav Malme e a flora do Rio Grande do Sul. Ciência \& Ambiente, Santa Maria, n. 13, p. 99-104, 1996.

BEBER. C. C. Santa Maria 200 anos: História da economia do município. Santa Maria: Pallotti, $1998.316 \mathrm{p}$.

BELTRÃO, R. Flórula fanerogâmica do município de Santa Maria, RS, Brasil. Boletim do Instituto de Ciências Naturais da Universidade de Santa Maria, Santa Maria, n. 1, p. 3-63, 1962.

BELTRÃO, R. Homenagem ao botânico desaparecido. Boletim do Instituto de Ciências Naturais da Universidade de Santa Maria, Santa Maria, n. 1, p. 89-94, 1962.

BELTRÃO, R. Paleontologia de Santa Maria e São Pedro do Sul, Rio Grande do Sul, Brasil. Boletim do Instituto de Ciências Naturais da Universidade Federal de Santa Maria, Santa Maria, n. 2, p. 3-114, 1965.

BELTRÃO, R. Flórula fanerogâmica do município de Santa Maria (primeiro suplemento). Boletim do Instituto de Ciências Naturais da Universidade Federal de Santa Maria, Santa Maria, n. 2, p. 115-151, 1965.

BELTRÃ̃, R. Cronologia histórica de Santa Maria e do extinto município de São Martinho. Canoas: Tipografia Editora La Salle, 1979. 582 p. 
BELTRÃO, R. O vanguardeiro de Itororó. Santa Maria: Câmara Municipal de Vereadores, 1998. 222p.

ISAIA, A. Os fascinantes caminhos da Paleontologia. Santa Maria: Dinotchê, 2008. 68 p.

JAEGER, L.G. As primeiras reduções jesuíticas no Rio Grande do Sul. In: Terra Farroupilha. Porto Alegre: Selbach, 1937. p. 32-51.

KAUSEL, E. Los tipos de Mirtaceas extrangeras conservados en el Herbario de Santiago. Revista Universitaria, Universidad Católica de Chile, Santiago, v. 35, n. 1, p. 135-146, 1950.

LINDMAN, C.A.M. A vegetação no Rio Grande do Sul. Porto Alegre: Typog. da "Livraria Universal" de Echenique Irmãos \& Cia, 1906. 356 p.

LINDMAN, C.A.M. A vegetação no Rio Grande do Sul. Belo Horizonte: Ed. Itatiaia, São Paulo: Ed. da Universidade de São Paulo, 1974. 377 p.

MARCHIORI, J.N.C. Arsène Isabelle. Ciência \& Ambiente, Santa Maria, n. 13, p. 55-72, 1996.

MARCHIORI, J.N.C.; DURLO, M.A. Friedrich Sellow e sua contribuição para as Ciências Naturais. Ciência \& Ambiente, Santa Maria, n. 16, p. 29-50, 1998.

MARCHIORI, J.N.C.; NOAL FILHO, V. Santa Maria: relatos e impressões de viagem. Santa Maria: Ed. da UFSM, 1997. 296 p.
PAVIANI, T. I. Determinação da viscosidade relativa das folhas de Hibiscus rosa-sinensis Linn. Boletim do Instituto de Ciências Naturais da Universidade de Santa Maria, Santa Maria, n. 1, p. 65-71, 1962.

PORTO, A. História das Missões Orientais do Uruguai. Porto Alegre: Selbach, 1954. v. 1.434 p.

RAU, W. Cedroxylon canoasense, una madera fósil nueva del Rio Grande del Sud. Revista Sudamericana de Botanica, Montevideo, v. 1, n. 3, p. 65-68, 1934.

RAU, W. Dadoxylon (Araucarioxylon) butiense $\mathrm{n}$. sp. Ein bertrag zur entwicklung der holzstruktur der Palaeozoischen Koniferen Rio Grande do Sul. Revista Sudamericana de Botanica, Montevideo, v. 1, n. 6, p. 169-172, 1933.

SAINT-HILAIRE, A. de. Viagem ao Rio Grande do Sul. Brasília: Senado Federal, Conselho Editorial, 2002. 575 p.

SANTOS, Z.L. dos. Histórico (1931-1961). In: 60 anos de ensino farmacêutico em Santa Maria, RS. Santa Maria: Imprensa Universitária/UFSM, 1991. p. 31-41.

TESCHAUER, C. Historia do Rio Grande do Sul dos dous primeiros seculos. Porto Alegre: Livraria Selbach, 1918. v. 1. 405 p. 